\title{
Medical students' perspective of maximum security psychiatric care
}

\author{
Lindsay D. G. Thomson, Colin M. Gray and Martin S. Humphreys
}

\begin{abstract}
Aims and method This study describes the effects of teaching medical students in a maximum security psychiatric setting. A questionnaire was distributed to students $(n=210)$ at the beginning and end of their third year.

Results Following the visit to the State Hospital significantly more students understood that maximum security psychiatric facilities are part of the National Health Service; that some serious offenders may require hospitalisation rather than imprisonment; that not everyone detained in such surroundings is actively violent or dangerous, or permanently detained. Twenty-three students considered forensic psychiatry to be a possible career option.

Clinical implications This study demonstrates that early exposure, even to such a specialised area of practice, can enhance the prospects of future recruitment. Attracting motivated, able and interested doctors is important in improving patient care.
\end{abstract}

For the past seven years medical students at the University of Edinburgh have visited the State Hospital, Carstairs as part of their third year psychiatry teaching. The State Hospital provides care for patients from Scotland and Northern Ireland with a mental disorder who have "dangerous, violent or criminal propensities", and is the equivalent of the English special hospitals. It has approximately 240 patients and about $70 \%$ have schizophrenia. Just over half were admitted directly as a result of an offence (Thomson et al, 1997).

Visits occupied one afternoon of the psychiatry course for each group of 10 students and ran throughout the year. On arrival at the State Hospital students were accompanied through the various security checks required and walked to a previously designated ward with their tutors. The unit used for teaching varied depending upon clinical, administrative, or more rarely, security considerations. Sessions were structured to promote interest, debate and an increased understanding of high security psychiatric care. There was an initial description and discussion of the role of the State Hospital and also of the patients who might be found there, and then a clinical case presentation at which students had the opportunity to meet the patient. Wider issues were then discussed, such as the differences between secure hospital facilities and prisons, the interface between psychiatry and the law, the ethics of compulsory detention and personality disorder and its treatment.

\section{The study}

A purpose designed questionnaire was distributed to all third year medical students at a psychiatry lecture prior to the first scheduled visit to the State Hospital. The students were asked to complete and return this immediately. The process was repeated towards the end of the summer term with a modified questionnaire. The two instruments had nine items in common.

\section{Findings}

Of 210 medical students in the year, $134(64 \%)$ completed the first questionnaire and 64 (30\%) the second.

\section{Questionnaire 1}

The average age of respondents was 20.8 years (range 19-31 years). There were 79 women and 54 men. One participant did not state his/her gender. One hundred students $(75 \%)$ had heard of the State Hospital prior to their visit. Broadmoor Hospital was known to $90(77 \%)$ subjects, while $18(13.4 \%)$ had heard of Ashworth and 16 (11.9\%) of Rampton Hospital.

\section{Questionnaire 2}

There were significant differences in the understanding and appreciation of issues related to maximum security psychiatric provision and care, and the patients who might require such facilities between administration of the first and second questionnaires (Table 1).

Three additional sections were included on the second occasion. All those who replied said that 
Table 1. Questionnaires 1 and 2

\begin{tabular}{|c|c|c|c|}
\hline Questions & Questionnaire 1 & Questionnaire 2 & $\chi^{2}$ \\
\hline $\begin{array}{l}\text { Are maximum security } \\
\text { (a) health services? } \\
\text { (b) prison services? } \\
\text { (c) blank/unknown? }\end{array}$ & $\begin{array}{l}75(56 \%) \\
53(39.5 \%) \\
6(4.5 \%)\end{array}$ & $\begin{array}{l}60(93.8 \%) \\
2(3.1 \%) \\
2(3.1 \%)\end{array}$ & $P<0.001$ \\
\hline \multicolumn{4}{|c|}{$\begin{array}{l}\text { Should individuals who commit a serious offence (i.e. } \\
\text { murder, arson, rape) ever be offered psychiatric } \\
\text { treatment? }\end{array}$} \\
\hline Yes & 133 (99.25\%) & 64 (100\%) & \\
\hline No & $1(0.75 \%)$ & 0 & NS \\
\hline \multicolumn{4}{|c|}{$\begin{array}{l}\text { Should serious offenders ever be admitted to hospital } \\
\text { rather than being sent to prison? }\end{array}$} \\
\hline Yes & $97(72.4 \%)$ & 59 (92.2\%) & \\
\hline No & $31(23.1 \%)$ & $3(4.7 \%)$ & \\
\hline Blank/unknown & $6(4.5 \%)$ & $2(3.1 \%)$ & $P<0.005$ \\
\hline \multicolumn{4}{|c|}{$\begin{array}{l}\text { Can serious offending ever be the result of mental } \\
\text { illness }\end{array}$} \\
\hline Yes & $133(99.25 \%)$ & 64 (100\%) & \\
\hline No & & & \\
\hline Blank/unknown & $1(0.75 \%)$ & & NS \\
\hline \multicolumn{4}{|c|}{$\begin{array}{l}\text { Have all those detained in high security psychiatric } \\
\text { facllities committed a serious crime? }\end{array}$} \\
\hline Yes & $10(7.5 \%)$ & $2(3.1 \%)$ & \\
\hline No & $122(91 \%)$ & $62(96.9 \%)$ & \\
\hline Blank/unknown & $2(1.5 \%)$ & & NS \\
\hline \multicolumn{4}{|c|}{$\begin{array}{l}\text { Are all those detained in such facilities } \\
\text { (a) violent? }\end{array}$} \\
\hline Yes & $24(17.9 \%)$ & 2 (3.1\%) & \\
\hline No & $108(80.6 \%)$ & 62 (96.9\%) & \\
\hline Blank/unknown & $2(1.5 \%)$ & & $P<0.01$ \\
\hline \multicolumn{4}{|l|}{ (b) dangerous? } \\
\hline No & $\begin{array}{l}14(30.2 \%) \\
55(41.0 \%)\end{array}$ & $42(65.6 \%)$ & \\
\hline Blank/unknown & $5(3.7 \%)$ & & $P<0.005$ \\
\hline \multicolumn{4}{|c|}{$\begin{array}{l}\text { Are those detained in maximum security care ever } \\
\text { released? }\end{array}$} \\
\hline Yes & 124 (92.5\%) & $64(100 \%)$ & \\
\hline No & $5(3.75 \%)$ & 0 & \\
\hline Blank/unknown & 5 (3.75\%) & & NS \\
\hline \multicolumn{4}{|c|}{$\begin{array}{l}\text { In your opinion should any of those detained in maximum } \\
\text { security psychiatric care ever be released? }\end{array}$} \\
\hline Yes & 107 (80\%) & 61 (95.3\%) & \\
\hline No & 19 (14\%) & & \\
\hline Blank/unknown & $8(6 \%)$ & $3(4.7 \%)$ & $P<0.01$ \\
\hline \multicolumn{4}{|c|}{$\begin{array}{l}\text { Physical measures (l.e. fence, electronic surveillance, } \\
\text { locked units) are the most important aspect of security } \\
\text { in such institutions }\end{array}$} \\
\hline Yes & 51 (38.1\%) & $23(35.9 \%)$ & \\
\hline No & $77(57.5 \%)$ & $38(59.4 \%)$ & \\
\hline Blank/unknown & $6(4.5 \%)$ & $3(4.7 \%)$ & NS \\
\hline
\end{tabular}

they found the visit to the State Hospital interesting and informative. Fifty-seven (89\%) students expressed an interest in finding out more about the subject. Twenty-three $(36 \%)$ said that they would consider a career in forensic psychiatry.

\section{Comment}

Nearly two-thirds of the year completed the first questionnaire, although less than a third returned the second. The decline was probably partly due to the considerably smaller number of 
students attending lectures towards the end of the summer term when examinations loomed. It is likely that those with more of an interest in, or knowledge of psychiatry returned the papers. This may be reflected in the fact that threequarters of those who responded knew of the State Hospital even before the first visit. It might also be indicative of regular media interest in the hospital.

Forty per cent thought that the State Hospital was a prison prior to their visit. After the visits more than $90 \%$ of the respondents said they were now aware that it was a health service facility. Generally the students did not have extreme views about mentally disordered offenders. They recognised the possibility of links between mental illness and serious offending. They accepted the prospect of mentally disordered offenders being admitted to hospital rather than being imprisoned or of patients being released from the State Hospital to local psychiatric facilities or back into the community even before the teaching sessions. Following their visits this was even more noticeable. Far more considered it appropriate that some individuals might need a psychiatric disposal rather than prison. There was also a significant change in the numbers who appreciated that not all patients in such establishments were unconditionally violent or dangerous.

The main aim of the teaching described here was to educate medical students about the practice of psychiatry in a secure setting and to set it in the context of other services. It was also designed to give some understanding of the patients who might require care in a secure environment. Students found the visit interesting, educational and enjoyable. This may in part be due to students feeling that the surroundings were exciting, much as they do on their first visit to a surgical theatre, but it is also likely that the interactive style of teaching employed and the clinical contact with a patient contributed to their positive experiences. Some psychiatrists have argued that such methods of teaching might encourage voyeurism and that it may not be appropriate for relatively inexperienced students to be taught about very specialised areas of work in an already potentially overcrowded medical curriculum. We would hold that it is a legitimate task to educate medical students about the place of such specialist facilities and to impart some understanding of the role of the forensic psychiatrist even at a relatively early stage in a medical career. Direct contact with patients who require care in conditions of special security can only serve to reduce stigma. Research by Baldwin et al (1998) has shown that the choice of psychiatry as a career is strongly influenced by undergraduate experience. This is born out by what we found here. In spite of the reduced numbers who returned the second questionnaire there was a substantial group who said they might consider forensic psychiatry as a career. This early interest may draw junior doctors into general psychiatry training, and following clinical experience into forensic psychiatry. Recruitment of motivated. able and interested individuals into small specialist areas is important. In this context the care and treatment of patients requiring forensic services, who can be seen as difficult or unattractive and consequently rejected or passed over, can only be improved as a consequence. The regular scrutiny by medical students and their tutors of the hospital encourages openness and examination of practice, and ensures that for this generation of student doctors such patients will not be out of sight and out of mind.

\section{References}

BALDWIN, P. J., DODD, M., Buckle, E. G., et al (1998) Medical careers: reason for choosing a particular speciality. Health Bulletin, 56, 498-503.

Thomson, L., Bogue, J.. Humphreys, M., et al (1997) The State Hospital Survey: a description of psychiatric patients in conditions of special security in Scotland. Journal of Forensic Psychiatry. 8. 263-284.

*Lindsay D. G. Thomson, Senior Lecturer in Forensic Psychiatry, The University of Edinburgh, Kennedy Tower, Morningside Park, Edinburgh EH1O 5HF, Colin M. Gray, Consultant Forensic Psychiatrist, The State Hospital, Carstairs; and Martin S. Humphreys, Senior Lecturer in Forensic Psychiatry. University of Birmingham

*Correspondence 